\title{
NOÇÕES DE MORFOSSINTAXE NOS PROCESSOS DE FORMAÇÃO DE PALAVRAS
}

\author{
MORPHOSYNTAX NOTIONS OF THE WORD FORMATION PROCESSES
}

\author{
Rosângela Gomes Ferreira DIVINO \\ UERJ/FFP \\ gfrosangela@gmail.com \\ José Augusto Oliveira PIRES \\ NEMP/UFRJ \\ augustopires2010@gmail.com
}

\begin{abstract}
Resumo: Este artigo tem por objetivo propor uma reflexão acerca do ensino de morfossintaxe do português brasileiro, a fim de contribuir com atividades que possam ajudar a professores da área sobre como lidar com o tema na sala de aula. Para abordar a questão, serão apresentadas propostas de como tratar das noções morfossintáticas nos processos de formação de palavras, ou seja, como os aspectos da morfossintaxe do português - conteúdo normalmente não agradável à maioria dos alunos e tido por eles como sem finalidade para entendimento e uso da língua - estão presentes não apenas nas orações, mas também em níveis menores, como nas palavras, em seus diversos processos de formação. A ideia é mostrar que essas operações refletem mecanismos conceptuais gerais, ou seja, formas de pensar e, por isso, estão presentes na língua, nos seus diversos níveis. Assim, esse estudo dialoga com premissas dos estudos cognitivistas, conforme Lakoff (1987), e também com os estudos recentes da gramática multissistêmica, de Castilho (2010), em especial com foco no dispositivo sociocognitivo, que afeta todos os sistemas linguísticos simultaneamente, ou seja, não há uma hierarquia entre os níveis da gramática. Este estudo, embora recorra a alguns aportes teóricos, como os mencionados acima, não se pautará em um em específico, visto que a proposta aqui não se trata de uma aplicação teórica, e sim visa a trazer contribuições para os profissionais de língua portuguesa em ensino médio e fundamental.
\end{abstract}

Palavras-chaves: Morfossintaxe. Formação de palavras. Ensino.

Abstract: This article aims to propose a reflection about the teaching of morphosyntax of Brazilian Portuguese, in order to contribute to activities that can help teachers on how to deal with this topic in the classroom. To address the issue, proposals on how to deal with the morphosyntactic concepts in word formation processes will be presented, that is, how the aspects of the morphosyntax of Portuguese - content not usually pleasant to most students and had by them as purposeless for understanding and use of language - are present not only in clauses but also at lower levels, as in the words, in their various word formation processes. The idea is to show that these operations reflect general conceptual mechanisms, that is, ways of thinking and, therefore, are present in the language, in its several levels. Thus, this study speaks with

Artigo recebido em 10/03/2016 e aceito em 20/06/2016. 
assumptions of cognitive studies, as Lakoff (1987), and also with recent studies of multisystem grammar, Castilho (2010), particularly focusing on the sociocognitive device, which affects all linguistic systems simultaneously, that is, there is not a hierarchy among the levels of grammar. This study, although refer to some theoretical contributions, as mentioned above shall not be founded on one in particular, since the proposal here it is not a theoretical application, but aims to bring contributions to the Portuguese-speaking professionals in high and elementary school.

Keywords: Morphosyntax. Word formation. Teaching.

\title{
Introdução
}

Morfossintaxe é o estudo de mecanismos linguísticos que envolvem as relações entre a morfologia e a sintaxe. Definidos como dois níveis de análise da língua distintos, o primeiro trata da estrutura e dos processos de flexão e formação de palavras, bem como, segundo as gramáticas, a discriminação dos vocábulos em classes gramaticais. A sintaxe, por sua vez, é a parte da gramática que define como as palavras se relacionam nas frases - o que engloba concordância, posição e subordinação - assim como as frases no discurso. Portanto, as descrições e análises em torno da morfossintaxe do português costumam pautar-se apenas nas palavras enquanto elementos de uma frase, seu papel sintático - no campo da sintaxe - e sua classe gramatical - no campo da morfologia - conforme se verifica no trecho a seguir:

\begin{abstract}
Não se pode separar o conhecimento morfológico do sintático, pois o primeiro propicia muito mais segurança na determinação das funções sintáticas dos termos da oração: a base ou a natureza morfológica de um sintagma (constituinte imediato das orações) determina ou autoriza sua função sintática. E a respeito de sintagmas, mostro que, aprendendo a reconhecê-los e decompô-los, a tarefa de observar-lhes as funções sintáticas fica extremamente mais fácil. Aí, sim, podem ser abordados todos os termos da oração, em um método muito prático e seguro de análise, até chegar a um verdadeiro quadro morfossintático desses termos. (SAUTCHUK, 2010, p. xviii)
\end{abstract}

Sobre essa questão, Henriques (2011, p. 8) faz a seguinte afirmação: “(...) o estudo da morfossintaxe só se concretiza no momento em que há a construção de um enunciado, isto é, A CONSTRUÇÃO DE UMA FRASE." (destaque no original). No entanto, este trabalho pretende desconstruir assertivas como essas, haja vista que o estudo das relações linguísticas 
analisadas no âmbito da morfossintaxe também se realiza no nível da palavra, em alguns processos formadores.

Objetivando contribuir com professores para o estudo de morfossintaxe da língua portuguesa, analisaremos e descreveremos algumas relações morfossintáticas presentes em processos de formação de palavras do português brasileiro. Cabe destacar que este é um trabalho inicial, cujo foco está em oferecer possíveis atividades e reflexões sobre mecanismos linguísticos que, com certa frequência, geram dúvidas aos alunos - que os veem apenas como um conjunto de nomenclaturas a serem decoradas -, mas que, se começarem a ser estudados em categorias linguísticas menores, talvez sejam mais bem assimilados. Assim, não há, aqui, a pretensão de abordarmos todas as classificações morfossintáticas, bem como todos os processos de formação de palavras existentes.

Para dar conta do propósito, o detalhamento deste trabalho será realizado da seguinte maneira: na próxima seção, retomaremos brevemente as noções estudadas em morfossintaxe nos ensinos fundamental e médio. Dando continuidade, mostraremos algumas delas no interior das palavras, mais especificamente daquelas construídas por processos de formação específicos. Por fim, listaremos atividades possíveis de serem feitas no ambiente escolar e os ganhos dessa abordagem, nas considerações finais do artigo.

\section{A tradição da morfossintaxe no âmbito escolar}

Hoje, muito se discute sobre a importância de os estudos como um todo possuírem uma capacidade reflexiva, interacionista com a realidade em que 0 aluno se insere, de modo a formar não apenas meros discentes "reprodutores de conteúdo", e sim de cidadãos mais conscientes do seu papel social, conforme apregoam os Parâmetros Curriculares Nacionais (doravante PCNs). Esse documento afirma o seguinte em termos proposta educacional:

No contexto da proposta dos Parâmetros Curriculares Nacionais se concebe a educação escolar como uma prática que tem a possibilidade de criar condições para que todos os 
alunos desenvolvam suas capacidades e aprendam os conteúdos necessários para construir instrumentos de compreensão da realidade e de participação em relações sociais, políticas e culturais diversificadas e cada vez mais amplas, condições estas fundamentais para o exercício da cidadania na construção de uma sociedade democrática e não excludente. (PCNs, 1997, p. 33)

Ademais, o mesmo documento também destaca o seguinte:

O exercício da cidadania exige 0 acesso de todos à totalidade dos recursos culturais relevantes para a intervenção e a participação responsável na vida social. O domínio da língua falada e escrita, os princípios da reflexão matemática, as coordenadas espaciais e temporais que organizam a percepção do mundo, os princípios da explicação científica, as condições de fruição da arte e das mensagens estéticas, domínios de saber tradicionalmente presentes nas diferentes concepções do papel da educação no mundo democrático, até outras tantas exigências que se impõem no mundo contemporâneo. (PCNs, 1997, p. 27)

Contrastando com a nova proposta apresentada nos PCNs, um estudo realizado por Neves (1990) mostrou que mais de 70\% das atividades propostas em salas de aula de nível fundamental e médio envolvem as áreas de estudo morfologia $(39,71 \%)$ e sintaxe $(35,85)$. Nesse sentido, percebe-se a importância de o estudo da língua portuguesa extrapolar a metalinguagem e, através da pluralidade de textos, levar o aluno à compreensão de sua língua, entendendo a sua estrutura e uso, tendo a capacidade de relacionar o conteúdo apreendido com a realidade com a qual se depara, bem como interpretá-la e entendê-la, conforme as orientações dos Parâmetros Curriculares Nacionais (doravante PCNs). Para tal, os PCNs, especificamente de Língua Portuguesa, destacam que:

Dessa perspectiva, a língua é um sistema de signos histórico e social que possibilita ao homem significar o mundo e a realidade. Assim, aprendê-la é aprender não só as palavras, mas também os seus significados culturais e, com eles, os modos pelos quais as pessoas do seu meio social entendem e interpretam a realidade e a si mesmas. (PCNs Língua Portuguesa, 1997, p. 22)

Assim é que podemos hipotetizar que, sendo a pesquisa de Neves de mais de 20 anos, teríamos uma realidade um pouco diferente, pois se preconiza a heterogeneidade de gêneros em sala de aula, incluindo os gêneros orais, e a valorização crítica do aluno em relação à sua língua. Porém, como profissionais também do Ensino Fundamental e Médio e professores de 
graduação em Letras e pós-graduação em Língua Portuguesa, temos nos deparado com uma realidade bem diferente dos conteúdos programáticos, em que ainda se 2priorizam as nomenclaturas e, dentre elas, as noções morfossintáticas.

Nesse sentido, o ensino de morfologia e sintaxe e, por conseguinte, morfossintaxe, ainda é demasiado. Sua aplicação pode, muitas vezes, não enfocar as nomenclaturas - como objeto indireto e complemento nominal - e sim as relações lógicas que determinam as funções das palavras num dado contexto - por exemplo, se um termo "aparece" na oração porque foi projetado por outro e qual seria esse termo -, mas, ainda assim, o estudo se baseia nas relações que se estabelecem entre classes de palavras e funções sintáticas, ou seja, quais as funções sintáticas que uma determinada palavra de uma dada classe gramatical pode exercer. Dito de outra maneira, as palavras de classes gramaticais específicas desempenham papéis específicos e ocupam posições pré-estabelecidas.

A título de exemplificação, vejamos as frases a seguir:

(01) Maria trabalha por dinheiro.

(02) Maria necessita de dinheiro.

(03) Maria tem necessidade de dinheiro.

(04) Minha bolsa de dinheiro foi roubada no aeroporto.

(05) Maria não quer dinheiro.

Em todas as sentenças, com base em uma perspectiva morfológica, temos a presença do substantivo "dinheiro". Em três delas (2, 3 e 4), o substantivo vem precedido da preposição "de". Em 1, vem antecedido de "por". No último exemplo (5), não há a presença de nenhuma preposição. Desta vez, sob o viés da sintaxe, ou seja, o papel que "dinheiro" exerce em cada um dos exemplos acima, temos, respectivamente:

(06) Maria trabalha por dinheiro. - ADJUNTO ADVERBIAL (DE CAUSA)

(07) Maria necessita de dinheiro. - OBJETO INDIRETO

(08) Maria tem necessidade de dinheiro. - COMPLEMENTO NOMINAL 
(09) Minha bolsa de dinheiro foi roubada no aeroporto. - ADJUNTO ADNOMINAL

(10) Maria não quer dinheiro. - OBJETO DIRETO

Nos exemplos (06), (07) e (10), "dinheiro" se relaciona com os verbos "trabalhar", "necessitar" e "querer", respectivamente; por sua vez, nas ilustrações restantes - (08) e (09) -, relaciona-se com os nomes "necessidade" e "bolsa" nessa ordem. Sendo assim, tratemos, primeiramente, dos exemplos que se relacionam com os verbos, passando, em seguida, para os que se relacionam aos nomes.

No caso (06), exerce a função sintática de adjunto adverbial, em decorrência de indicar uma circunstância, ou seja, expressa uma noção semântica, mais especificamente de causa; o motivo do trabalho de Maria é a busca por dinheiro. Para o exemplo (07), temos um caso de objeto indireto, pois "dinheiro" complementa o sentido de um verbo que exige uma preposição: necessita de quê? No (10), como "dinheiro" complementa o sentido de um verbo que não exige preposição - verbo querer -, temos um caso de objeto direto: quer o quê? Agora, analisemos os exemplos (08) e (09).

Em (08), "de dinheiro" se relaciona com o nome "necessidade". Com base em uma análise pautada em gramáticas normativas, como se trata de um substantivo abstrato, e ainda notamos uma noção de passividade - o dinheiro é necessitado -, constatamos que se trata de um caso de complemento nominal. Na ilustração (09), "de dinheiro" está ligado ao nome "bolsa". Já que se trata de um substantivo concreto, a expressão é classificada sintaticamente como um adjunto adnominal.

Um outro aspecto a ser considerado nos exemplos mencionados diz respeito a funções nucleares e não-nucleares, ou seja, de adjuntos.

Em (07), (08) e (10), as respectivas funções de objeto indireto, complemento nominal e objeto direto são nucleares, pois integram o sentido de verbos - (07) e (10) - e de um nome (08). Por sua vez, em (06) e (09), as funções de adjunto adverbial (de causa) e adjunto adnominal, nessa ordem, são não-nucleares, isto é, adjuntos, em decorrência de modificarem o sentido 
de um verbo ou de um nome, mas que podem, em termos sintáticos, ser suprimidas das frases.

Com isso, baseado na descrição acima, notamos que um mesmo vocábulo pode desempenhar diversos papéis, a depender do contexto em que se insere, bem como seu uso. Dito de outra forma, o estudo entre a seleção vocabular - âmbito da morfologia - e sua respectiva função em uma determinada frase - âmbito da sintaxe - proporcionam uma análise morfossintática, a qual ainda se mostra predominante nas salas de aula.

Um outro exemplo da abordagem a respeito de funções nucleares e nãonucleares é a inversão de ordem de dois substantivos que atuam num mesmo sintagma nominal ${ }^{1}$, como se verifica no célebre exemplo de Machado de Assis, em sua obra clássica "Memórias Póstumas de Brás Cubas", ao dizer que não é um "autor defunto" e sim um "defunto autor". No primeiro caso, "autor" é o núcleo, ou seja, o termo central da construção, aquele cujo sentido é basilar, e "defunto" é, por seu turno, adjunto adnominal, sendo modificador de "autor". Com a inversão de ordem, "defunto" passa a ser núcleo e "autor", adnominal.

Os efeitos de sentido com a mudança de posição também devem ser analisados: "autor defunto" é um autor que morre, enquanto "defunto autor" é um morto que escreve.

O estudo tradicional de morfossintaxe trata de questões como as descritas nesta seção, e que serão retomadas na seção a seguir, quando analisaremos esses mecanismos linguísticos no âmbito intralexical.

\section{A nossa proposta para o estudo de morfossintaxe no nível interno da palavra}

Aportes teóricos recentes têm defendido que não há independência entre os princípios cognitivos e os que atuam na formação da linguagem, o chamado Princípio da Invariância para os cognitivistas (LAKOFF, 1987). Entende-se que a linguagem não é autônoma e reflete princípios cognitivos gerais, sendo a

\footnotetext{
${ }^{1}$ Sintagma nominal é uma unidade da oração que sempre terá como núcleo um substantivo.
} 
gramática, portanto, motivada por esses processos, que, por sua vez, irão aparecer no funcionamento da gramática. Nesse sentido, não há fronteiras nítidas entre os diversos níveis da gramática, o que quer dizer que os mesmos mecanismos conceptuais irão atuar na fonologia, na morfologia, na sintaxe, na semântica e na pragmática.

De forma análoga, a teoria multissistêmica funcionalista-cognitivista (CASTILHO, 2010) preconiza que a língua é feita de um conjunto de sistemas, conforme o gráfico a seguir:

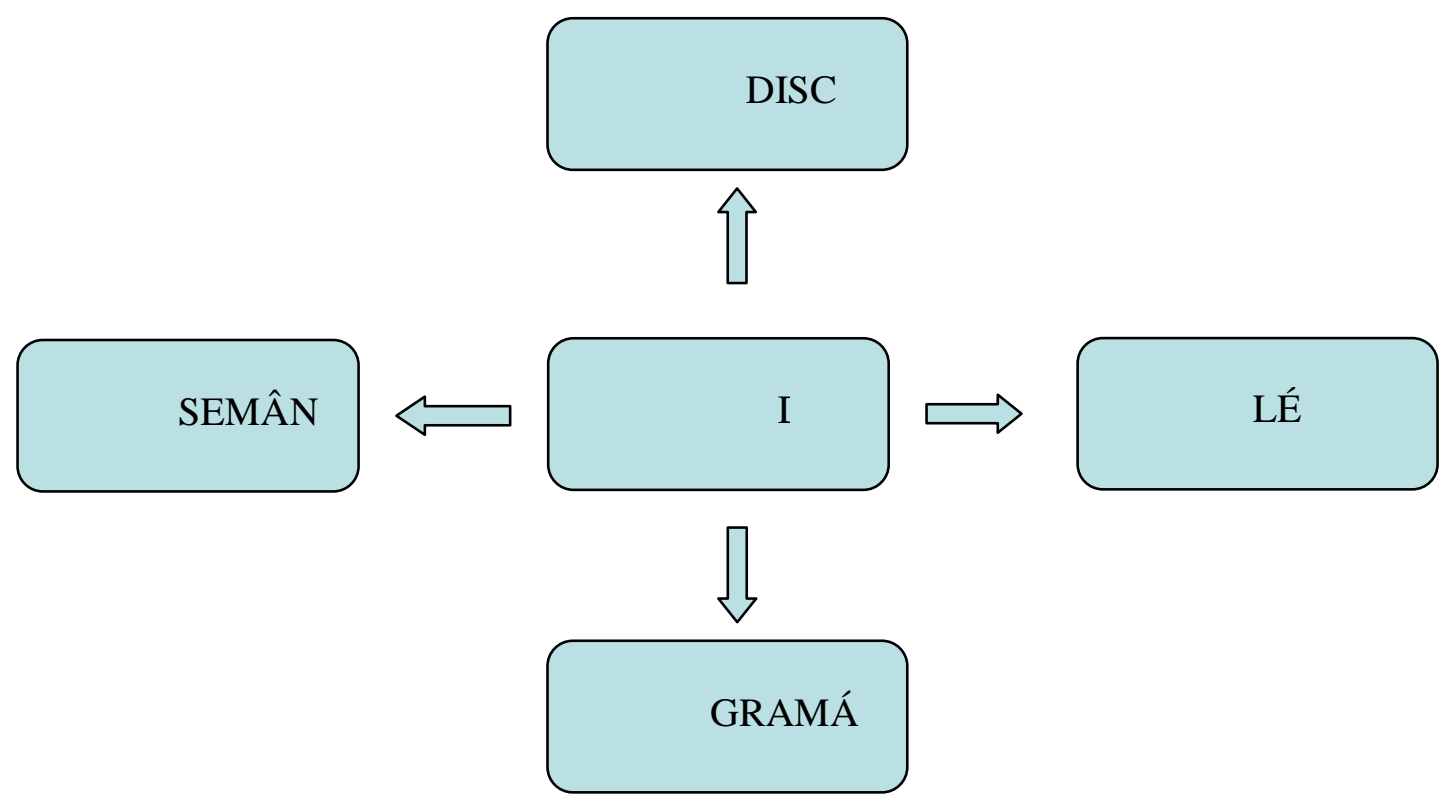

Figura 1: Representação gráfica dos sistemas de que é feita a língua (CASTILHO, 2010, p.

69)

Castilho (2010:69) explica que, no gráfico acima, DSC significa "dispositivo sociocognitivo" e é o mecanismo que se liga a todos os sistemas linguísticos. Fica evidente que, para ele, a língua também não é uma unidade autônoma por se fundamentar em um "aparato cognitivo". O autor postula, dentre outras premissas, que "as estruturas linguísticas são multissistêmicas, ultrapassando os limites da gramática" (op. cit.).

Essas são as noções que permeiam a nossa proposta: se há um DSC que se liga a todos os sistemas linguísticos e não há fronteiras nítidas entre os 
diversos níveis da gramática, é possível que os mesmos mecanismos sintáticos ou morfossintáticos que ocorrem entre as palavras no âmbito da oração ocorram internamente nas palavras. Em outras palavras, significa dizer que os mesmos mecanismos cognitivos também poderiam atuar nas estruturas das palavras e frases.

Tal perspectiva também contempla os estudos que defendem um único fenômeno na língua a ser estudado do ponto de vista das diversas áreas da gramática e não apenas pertencendo a uma delas. Basílio (2004:4) se apropria dessa ideia ao tratar de classes de palavras, quando afirma "que os processos de formação de palavras apresentam tanto funções gramaticais quanto funções semânticas; e seus produtos, as palavras formadas através de sua operação, apresentam propriedades morfológicas, sintáticas e semânticas".

Graça Rio-Torto (1998) também dialoga com essa proposta, ao retratar como deve se dar o estudo de formação de palavras:

\begin{abstract}
A formação de palavras é uma área da atividade linguística cujo funcionamento envolve todas as demais áreas da língua.

Ela está em relação com a lexicologia, porquanto é ao léxico, entendido como repositório de entidades lexicais susceptíveis de construir novas palavras, que ela vai buscar a matéria prima de que se serve para dar origem a novos produtos lexicais.

Ela está em conexão com a morfologia, na medida em que a produção de novas palavras implica a emergência de estruturas lexicais compósitas que envolvem a comparticipação de bases e de entidades afixais.

Ela tem afinidade com a morfossintaxe e com a semântica, desde logo porque a formação de palavras se define pela combinatória de elementos. Mas também porque os produtos derivacionais são marcados por determinada categoria sintático-semântico, e porque as operações/os operadores derivacionais têm poderes de categorização e de subcategorização, chegando mesmo a alterar a estrutura argumental das bases.

Na medida em que manipula estrutura morfossintático-lexicais, não apenas pelo que elas são em si mesmas, mas sobretudo pelas suas potencialidades combinatórias, a formação de palavras opera com as dimensões fonológica e semântica da língua. (RIOTORTO, 1998, p. 72)
\end{abstract}

Segundo as autoras, tanto o fenômeno das classes gramaticais - que costuma ser estudado no âmbito morfológico ou morfossintático - como os processos de formação de palavras devem ser estudados envolvendo todos os sistemas de análise da língua.

Neste artigo, vamos identificar em processos de formação de palavras alguns mecanismos sintáticos, comumente estudados no nível das orações. 


\subsection{Os processos de formação de palavras}

Segundo gramáticas tradicionais, os mecanismos mais gerais de formação de palavras são dois: derivação e composição.

Cunha \& Cintra (2001 [1985], p. 83) elucidam, sobre isso, da seguinte maneira: "Chama-se formação de palavras o conjunto de processos morfossintáticos que permitem a criação de unidades novas com base em morfemas lexicais. Utilizam-se assim, para formar as palavras, os afixos de derivação ou os procedimentos de composição".

Por essa razão, é que vamos nos ater aqui, predominantemente, a esses dois processos: derivação e composição.

O processo de derivação é definido tradicionalmente como palavras formadas por um só radical, a que se anexam afixos (prefixos e sufixos). Nada é dito acerca do funcionamento sintático desses sufixos, apenas o fato de atribuírem um novo sentido ao radical e, por isso, formarem uma nova palavra na língua.

Gonçalves (2007) mostrou, ao descrever critérios que diferem a flexão da derivação, que as palavras formadas pelo processo de derivação sufixal têm seu núcleo semântico nos sufixos, enquanto os radicais seriam os adjuntos adnominais das formações. As formas "goiabeira", "livraria", "milharal", "assustador", correspondem a árvore da goiaba, lugar que vende livros, plantação de milho e aquilo que assusta, respectivamente. Em todos os casos, o morfema - parte significativa da palavra - que determina o sentido nuclear é o sufixo:

Goiabeira = eira expressa árvore

Livraria = aria expressa lugar

Milharal $=$ al expressa plantação

Assustador $=$ dor expressa aquilo

De forma contrária, nas formações de derivação prefixal, o prefixo é adjunto, enquanto os radicais, nesses casos, são os núcleos. No caso dos 
prefixos que se juntam a bases verbais, os adjuntos são adverbiais, visto que não seria possível adjunto adnominal fazer referência a verbos, mas somente a substantivos. Vejamos alguns exemplos:

Renascer $=$ nascer de novo

Preceder $=$ ceder anteriormente

Transformar $=$ formar de outra maneira

Imigrar = migrar para dentro

No processo de composição, que envolve junção de uma base à outra, evidenciam-se, também, as noções de núcleo e adjunto. A composição é um processo de formação de palavras que utiliza fragmentos de estruturas sintáticas para fins lexicais, ou seja, mecanismos ou estruturas que são normalmente utilizados na formação de enunciados passam a ser utilizados na função de denominar e/ou caracterizar seres, que é uma função fundamental do léxico. Há três estruturas recorrentes para a formação de compostos:

Substantivo + substantivo, em que o primeiro substantivo funciona como núcleo da construção e o segundo como adjunto, como normalmente ocorre nas formações sintáticas gerais, visto que a posição default do adjetivo é após o substantivo: sofá-cama, couve-flor, salário-família, operário-padrão.

Substantivo + adjetivo ou adjetivo + substantivo, em que o núcleo é o

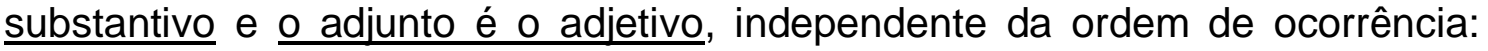
obra-prima, livre-arbítrio, carta-branca, secretária-eletrônica, alto-mar. Somamse a esses exemplos as formações com locuções adjetivas, como cabeça de vento, pão de ló, maça do amor.

Verbo+substantivo, em que o substantivo tem função análoga à de objeto direto do verbo: guarda-roupa, mata-mosquito, porta-retrato, beija-flor. $\mathrm{O}$ verbo, nessas formações, é sempre transitivo direto.

Há, ainda, outros processos de formação de palavras, tidos como não concatenativos ou não-lineares, que retratam relações existentes no nível morfossintático das orações.

O processo de substituição sublexical (FURTADO, 2011), estudado por Gonçalves (2016) como um tipo de cruzamento vocabular, é "uma sequência 
fonológica de uma das palavras interpretada morfologicamente e substituída" (GONÇALVES, 2016, p. 78).

Nesses casos, identificamos que a parte não morfêmica interpretada como um morfema e substituída por outra será sempre adjunto em relação ao radical, que, por sua vez, será interpretado sintática e semanticamente como núcleo. Vejamos:

Boadrasta - "boa" substitui a sequência "ma", interpretada pelo falante como sendo o adjetivo "má". Por essa razão, o sentido de "boa" é adjetivo, ou seja, exerce o papel de adjunto adnominal em relação à "drasta”, que passa a designar sozinho toda a formação "madrasta", para referir-se à esposa do pai. Isso fica ainda mais evidente ao analisarmos as formações mãedrasta e vódrasta, em que as formas "mãe" e "vó" aparecem caracterizando o tipo de madrasta, isto é, madrasta que é como mãe ou como avó.

Trêbado, zêbado = as sequências fônicas "trê" e "zê" atuam substituindo a forma "bê", reanalisada como "bi", ou seja, "duas vezes". Assim, "trê" seria um intensificador, reanalisado como "tri", e expressaria "três vezes", enquanto "zê" seria o máximo de intensificação, visto que chegou ao nível em que não se consegue mensurar, como em "zilhão". O mesmo acontece em exemplos como "tricha", substituição sublexical de "bicha". Por atuarem como intensificadores de nomes, seriam adjuntos adnominais.

Bebemorar = a sequência fônica "bebe" substitui "come", reanalisado como o tema do verbo "comer". Portanto, "comemorar" seria uma formação que expressa comemorar "com comida", e, assim, "bebemorar" seria comemorar "com bebida". Por estar se referindo a verbo e expressar uma circunstância em relação ao verbo, seriam adjuntos adverbiais.

A seguir, apresentaremos possibilidades de como trabalhar essas reflexões na educação básica.

\section{Algumas reflexões para o ensino}


Como foi exposto anteriormente, o objetivo deste artigo é apontar relações morfossintáticas que extrapolam o nível da oração, sendo recorrentes no nível do interior das palavras, de acordo com o processo de formação pelo qual ela foi formada. Esse estudo visa a contribuir com os professores, trazendo uma nova abordagem para questões que costumam ser associadas somente no nível dos enunciados e são motivo de insatisfação dos estudantes, por não perceberem a sua real finalidade.

Sendo assim, agora, iremos propor algumas atividades para 0 reconhecimento dessas noções, bem como os efeitos do uso morfológico e/ou sintático, a fim de despertar um olhar mais crítico dos alunos, e, consequentemente, a compreensão sobre a língua, bem como o reconhecimento desses usos nos diversos gêneros textuais distintos, tais como orientam os PCNs.

\section{Atividade 1:}

A imagem a seguir traz um cartaz exposto em um protesto contra a legalização da maconha².

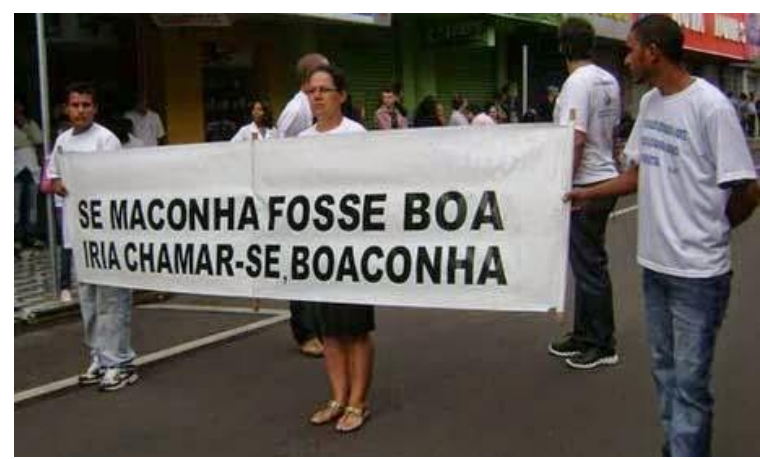

A imagem traz o neologismo "boaconha", substituição sublexical similar a "boadrasta". É interessante fazer com que os alunos percebam que a nova palavra se assemelha à noção de maconha boa, mas o efeito de sentido gerado pela formação morfológica é diferente do que seria na formação 
sintática, visto que a noção de boa estaria presente no próprio nome. Apesar disso, em ambos os casos, boa seria uma característica da maconha, ou seja, um adjetivo e teria função de adjunto adnominal, portanto.

\section{Atividade 2:}

A formação do plural dos substantivos compostos depende da classe das palavras que formam o composto, da grafia (com hífen ou sem hífen) e da relação que estabelecem entre si. Normalmente, os compêndios gramaticais de língua portuguesa listam uma série de regras para que se assimile a formação de tais plurais. É interessante fazer os alunos perceberem que o plural dos compostos segue as mesmas regras de concordância existentes nas formações sintáticas dentro das orações. Assim, não seria, por exemplo, necessário, dizer que

1) flexionam-se os dois elementos, em formações substantivo + adjetivo ( amor-perfeito e amores-perfeitos), adjetivo + substantivo (gentilhomem e gentis-homens), numeral + substantivo (quinta-feira e quintasfeiras), já que os numerais e adjetivos sempre concordam com o substantivo a que se referem.

2) flexiona-se somente o segundo elemento, em formações verbo + substantivo (guarda-roupa e guarda-roupas) e palavra invariável + palavra variável (alto-falante e alto-falantes), pois palavras invariáveis nunca flexionam e verbo possui mecanismos de flexão diferentes dos nomes.

$\mathrm{E}$, assim, também nos demais casos de formação dos compostos.

\section{Atividade 3:}

As manchetes abaixo mostram que os jornais, veículos cujos textos, em sua maioria, devem ser impessoais, dão preferência a estruturas sintáticas e não morfológicas no uso de adjuntos adnominais - "pacotes de bondades" (e não bondosos), "fiscalização do governo" (e não governamental), "igreja da Polônia" (igreja polonesa), "poderes do mundo" (poderes mundanos). É interessante mostrar aos alunos a objetividade das formações sintáticas em 
relação a uma subjetividade das construções sintéticas, ou seja, morfológicas e, em alguns casos, a diferença de sentido, como na última manchete, com "doces portugueses" (e não doces de Portugal).

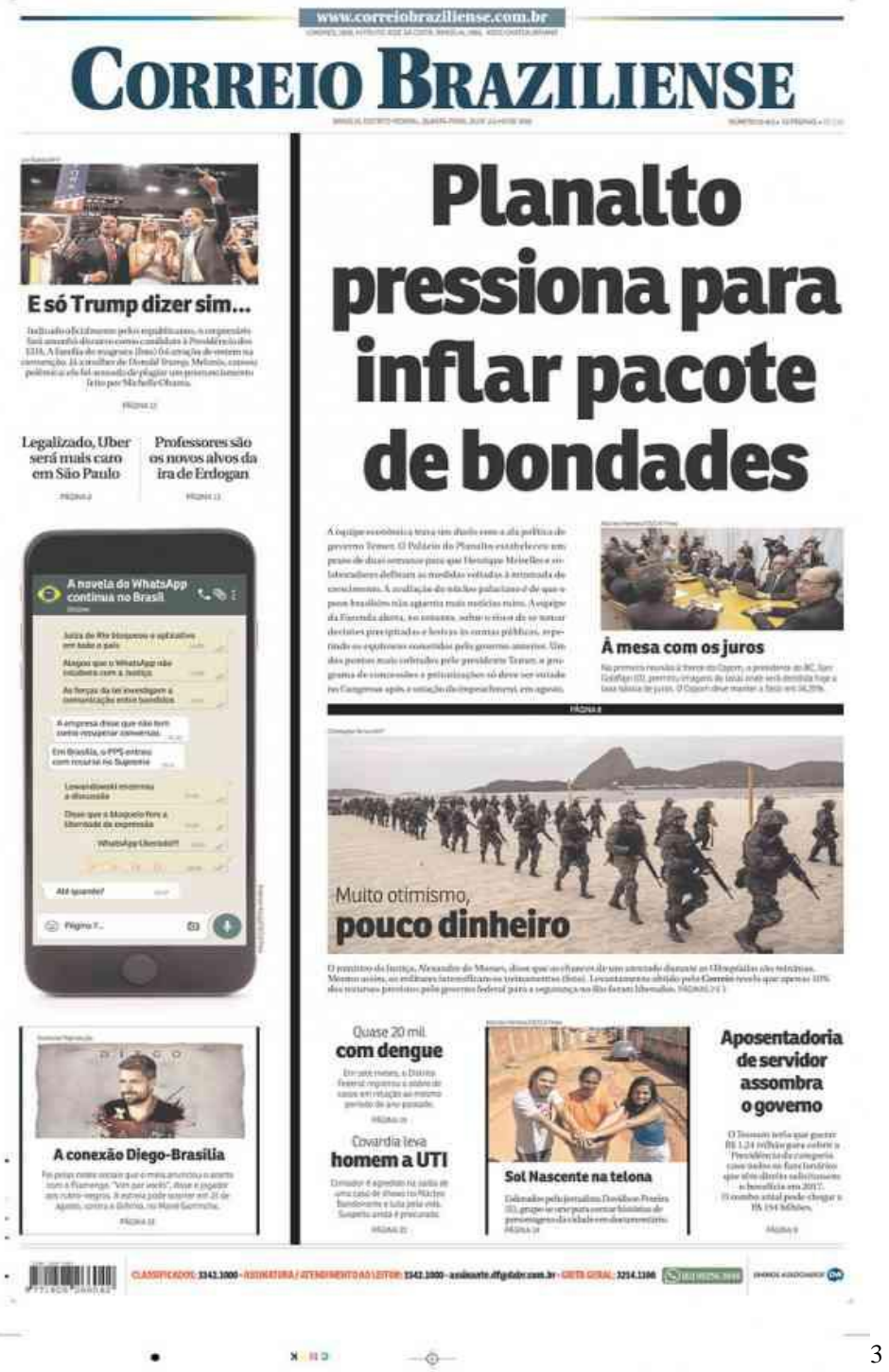

As notícias abaixo foram extraídas da Folha de São Paulo, http://www.folha.uol. com.br/, em 29/07/2016.

"Fiscalização do governo encontra falhas no programa Mais Médicos" "Papa Francisco pede que igreja da Polônia fuja de 'poderes do mundo"

\footnotetext{
${ }^{3}$ http://www.manchetesdosjornais.com.br/
} 
"Nova padaria tem pães fermentados naturalmente e doces portugueses"

\section{Considerações finais}

O presente artigo teve como objetivo realizar uma abordagem distinta sobre o ensino de morfossintaxe no português brasileiro, a fim de cooperar com o tema no âmbito escolar, tanto no ensino fundamental quanto no médio. Tendo em vista que os estudos de morfologia e de sintaxe e, por conseguinte, de morfossintaxe são predominantes, o intuito do trabalho foi o de propor uma descrição de questões sempre estudadas no âmbito de enunciados, ou seja, frase e oração, mas que também podem aparecer no interior das palavras. Isso ocorre porque a língua reflete processos cognitivos e, dessa maneira, não há distinção clara entre as diversas áreas da gramática.

Esperamos ter exemplificado relações de morfossintaxe em vocábulos através das análises de alguns processos de formação de palavras, sejam eles concatenativos - derivação e composição -, sejam eles não-concatenativos substituição sublexical. Ao se detalhar a morfossintaxe no nível das palavras, notamos frequentemente a existência recorrente de uma relação núcleoadjunto. Em outras palavras, significa dizer que nessas formações, há sempre a presença de um elemento que é basilar, no caso, o núcleo, e outro que é periférico, ou seja, adjunto. Essas são noções fundamentais para o entendimento das funções sintáticas, inclusive no período composto, com as classificações de orações subordinadas substantivas, adjetivas ou adverbiais. Entendidos esses conceitos com base no estudo da estrutura e formação de palavras, não seria difícil expandi-los para o estudo das orações. Por fim, algumas propostas de atividades foram lançadas.

\section{Referências bibliográficas}

BASÍLIO, M. Teoria Lexical. 8. ed. São Paulo: Ática, 2007[1988].

Formação de classes de palavras no português do Brasil. São Paulo: Contexto, 2004. 
CASTILHO, A. T. de. Nova Gramática do português brasileiro. 1. ed., 1. Reimpressão. São Paulo: Contexto, 2010.

CUNHA, Cunha; CINTRA, Lindley. F. L. Nova gramática do português contemporâneo. 3. ed. 7. Impressão, Rio de Janeiro: Nova Fronteira, 2001[1985].

FURTADO, L. R. Análise semântico-cognitiva das substituições sublexicais em português. 74f. Dissertação (Mestrado em Língua Portuguesa) - Faculdade de Letras, Universidade Federal do Rio de Janeiro, Rio de Janeiro, 2010.

GONÇALVES, C. A. Atuais tendências em formação de palavras. São Paulo: Contexto, 2016.

"Flexão e Derivação: o grau". In: Ensino de gramática: descrição e uso. VIEIRA, Silvia Rodrigues. BRANDÂO, Silvia Figueiredo (org.). São Paulo, Contexto, 2007.

HENRIQUES, C. C. Sintaxe: estudos descritivos da frase e exercícios com respostas. 3. ed. Rio de Janeiro: Elsevier, 2011.

LAKOFF, G. Women, fire and dangerous things: what categories reveal about the mind. Chicago: University Press, 1987.

RIO-TORTO, M. G. Morfologia Derivacional - Teoria e Aplicação ao Português. PORTO CODEX: Porto Editora, 1998.

SAUTCHUK, I. Prática de morfossintaxe: como e por que aprender análise (morfo)sintática. 2. ed. Barueri, SP: Manole, 2010.

Parâmetros curriculares nacionais: introdução aos parâmetros curriculares nacionais / Secretaria de Educação Fundamental. - Brasília: MEC/SEF, 1997. 
Parâmetros curriculares nacionais: língua portuguesa / Secretaria de Educação Fundamental. - Brasília: MEC/SEF, 1997. 